\title{
In situ effect of titanium tetrafluoride varnish on enamel demineralization
}

\section{Adílis Kalina ALEXANDRIA $^{(a)}$ Camila NASSUR(a) \\ Carolina Bezerra Cavalcanti NÓBREGA ${ }^{(b)}$ \\ Ana Maria Gondim VALENÇA ${ }^{(c)}$ Pedro Luiz ROSALEN(d) \\ Lucianne Cople MAIA(a)}

\footnotetext{
(a) Universidade Federal do Rio de Janeiro UFRJ, Rio de Janeiro Dental School, Department of Pediatric Dentistry and Orthodontics, Rio de Janeiro, RJ, Brazil.

(b) Universidade Federal de Campina Grande UFCG, Center for Rural Health and Technology, Campina Grande, PB, Brazil.

(c) Universidade Federal da Paraíba - UFPB, Dental School, Department of Clinical and Social Dentistry, João Pessoa, PB, Brazil .

(d) Universidade de Campinas - Unicamp, Piracicaba Dental School, Department of Pharmacology, Anesthesiology, and Therapeutics, Piracicaba, SP, Brazil.
}

Declaration of Interests: The authors certify that they have no commercial or associative interest that represents a conflict of interest in connection with the manuscript.

\section{Corresponding Author:}

Lucianne Cople Maia

E-mail: rorefa@terra.com.br

https://doi.org/10.1590/1807-3107BOR-2017.vol31.0086

Submitted: March 03, 2017

Accepted for publication: July 27, 2017

Last revision: August 24, 2017
Abstract: The effect of a $4 \%$ titanium tetrafluoride $\left(\mathrm{TiF}_{4}\right)$ varnish on enamel demineralization was evaluated. Twelve volunteers participated in this double-blind, randomized crossover study. Six enamel specimens were positioned in intraoral appliances throughout four treatment stages: $4 \% \mathrm{TiF}_{4}$ varnish (experimental varnish), $5 \%$ sodium fluoride $(\mathrm{NaF})$ varnish $\left(\right.$ Duraphat $\left.^{\circledR}\right)$, placebo varnish, and negative control (deionized water). After $24 \mathrm{~h}$, the varnishes were removed and plaques were allowed to accumulate. A $20 \%$ sucrose solution was dripped onto enamel blocks (10x/day). Enamel alterations were analyzed by surface microhardness (SMH), percentage of surface loss (\%SML), cross-sectional microhardness (CSMH), scanning electron microscopy (SEM), and energy dispersive X-ray spectrometry (EDS). Student's paired t-test was used for $\mathrm{SMH}$ analysis and repeated-measures analysis of variance (ANOVA) for \%SML and CSMH $(\Delta \mathrm{Z})$ analyses ( $p$-value=0.05). The $\mathrm{TiF}_{4}$ varnish group had lower \%SML than the placebo and control groups ( $p=0.044$ and $p=0.003$, respectively), thus showing its capacity to inhibit surface demineralization. $\mathrm{TiF}_{4}$ and $\mathrm{NaF}$ varnishes demonstrated a protective effect against mineral loss on the enamel subsurface. Both were statistically different from the control group when CSMH was analyzed $(\mathrm{p}=0.000)$. A titanium dioxide film was observed on enamel surfaces of the $\mathrm{TiF}_{4}$ group SEM images. EDS confirmed the presence of titanium in all $\mathrm{TiF}_{4}$ samples. The $4 \% \mathrm{TiF}_{4}$ varnish is a promising compound capable of reacting with enamel to protect it against surface and subsurface demineralization.

Keywords: Fluorides; Tooth Demineralization; Biofilms.

\section{Introduction}

Fluoride (F) products have been widely used in the prevention and control of caries and the fluoride ion $(\mathrm{F}-)$ present in these products has been considered the major determining factor for caries reduction in most industrialized countries. ${ }^{1,2}$ Topical fluoride agents are known to promote remineralization and inhibit demineralization of dental hard tissues due to calcium fluoride $\left(\mathrm{CaF}_{2}\right)$ reservoir., ${ }^{1,3}$

The formation of $\mathrm{CaF}_{2}$ and its protective effect on demineralization depend on $\mathrm{pH}$, fluoride ion concentration, and type of fluoride salt. ${ }^{3}$ In a cariogenic challenge, $\mathrm{F}$ released from the $\mathrm{CaF}_{2}$ reservoir may diffuse into the enamel and bind to apatite. ${ }^{3}$ 
Most commercially available dental varnishes contain sodium fluoride (NaF) and some authors have investigated other $\mathrm{F}$ compounds such as titanium tetrafluoride $\left(\mathrm{TiF}_{4}\right)$ for the prevention of enamel demineralization. ${ }^{4,5,6,7,8}$

Titanium tetrafluoride is a fluoridated compound with low acid solubility and resistance to corrosion. It has a profound ability to protect against demineralization due to the deposition of $\mathrm{CaF}_{2}$ and formation of an acidresistant titanium dioxide $\left(\mathrm{TiO}_{2}\right)$ layer on the enamel. ${ }^{4,910,11}$

$\mathrm{TiF}_{4}$ solution is a promising anticaries compound, but it is unstable and presents a low $\mathrm{pH}$ value and, because of that, it is not well accepted for clinical use. ${ }^{9}$ To overcome this problem, some authors tested the anticaries ${ }^{6}$ and antierosive ${ }^{12}$ potential of a $\mathrm{TiF}_{4}$ varnish. However, other studies are needed to elucidate the effect of $\mathrm{TiF}_{4}$ varnish in a situation that mimics the oral environment as in an in situ model.

The null hypothesis of this study was that the single application of $\mathrm{TiF}_{4}$ varnishes does not reduce surface and subsurface demineralization after cariogenic challenge in comparison with $\mathrm{NaF}$ varnish.

\section{Methodology}

\section{Study design}

This double-blind, randomized, crossover, in situ study was approved by the Research Ethics Committee of the Federal University of Rio de Janeiro (process number: 48/2010) and was performed with undergraduate and graduate dental students who signed an informed written consent for their participation.

Twelve healthy adult volunteers (aged 19-31 years) met the inclusion criteria proposed by Zero ${ }^{13}$ for in situ studies and did not violate the main exclusion criterion, i.e., use of any antibiotics or any other medication 60 days prior to the study and throughout the experimental stages.

The sample size was calculated based on a 0.8 power to detect a significant difference of $50 \%$ in mean mineral loss $(\Delta \mathrm{Z})$ in each treatment group (4\% titanium tetrafluoride varnish $-2.45 \% \mathrm{~F}$ - experimental varnish; sodium fluoride varnish - Duraphat ${ }^{\circledR}$ $2.26 \% \mathrm{~F}$ - regarded as the "gold standard") compared to control (placebo varnish - no-F; vehicle control), using a one-sided test with $5 \%$ significance level
(BioEstat 5.3, Instituto de Desenvolvimento Sustentável Mamirauá, Tefé, AM, Brazil) according to the results of a previous study with $4 \% \mathrm{TiF}_{4}$ solution. ${ }^{7}$ For this statistical power, a minimum of nine volunteers would be required. Sample size was calculated considering a crossover in situ design. For an estimated loss of $25 \%$, the sample should include 12 volunteers.

This study was performed in four 14-day stages, in which volunteers wore acrylic palatal appliances containing six sound bovine enamel blocks (three on each side) placed $1 \mathrm{~mm}$ below the acrylic level. The appliances containing the enamel blocks were sterilized with ethylene oxide before each stage. Volunteers were randomly allocated to each stage and received treatment accordingly (Figure 1).

\section{Specimen preparation}

Enamel blocks $\left(4 \times 4 \times 2 \mathrm{~mm}^{3}\right)$ were obtained from bovine incisors with sound crowns using water-cooled diamond discs (Buehler, Lake Bluff, IL, USA). The enamel surface was then polished with 600- and 1200-grit silicon carbide paper (Extec, Enfield, CT, USA), followed by a $1-\mu \mathrm{m}$ diamond abrasive slurry (Buehler, Lake Bluff, IL, USA). A total of 288 blocks were selected based on their baseline surface microhardness (SMH) (mean $341.59 \pm 34.15)$. $\mathrm{SMH}$ was measured using a microhardness tester (HVS-1000; Time Group Inc., Beijing, China) with a Knoop diamond indenter under a $50 \mathrm{~g}$ load for $5 \mathrm{~s}$, by making five indentations spaced $100 \mu \mathrm{m}$ from one another at the center of the enamel surface. ${ }^{7,14}$

\section{Specimen treatment}

At the beginning of each stage, volunteers placed the device in their mouths and kept it there for $5 \mathrm{~min}$. The appliances were then removed from the volunteers' mouths, and the enamel specimens were randomly treated according to the selection made for each stage: $4 \%$ titanium tetrafluoride varnish (2.45\% fluoride; experimental varnish), sodium fluoride $(\mathrm{NaF})$ varnish $\left(\right.$ Duraphat ${ }^{\circledR}, 2.26 \%$ fluoride, regarded as the "gold standard"), placebo varnish (no-fluoride; vehicle control), and negative control (deionized water). The treatments were applied onto the enamel surface using a microbrush (Microbrush Corp., Grafton, WI, USA). 
(A) Cutting Teeth

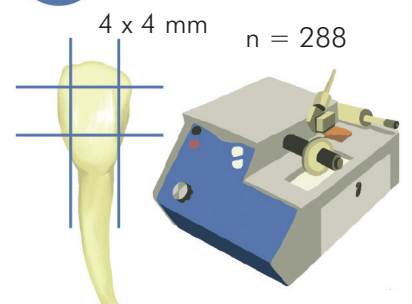

F Ethylene Oxide Sterilization
(B)

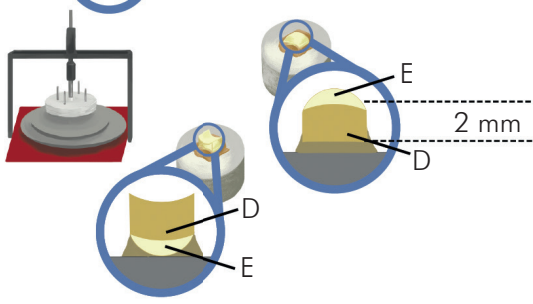

E

Appliance Preparation
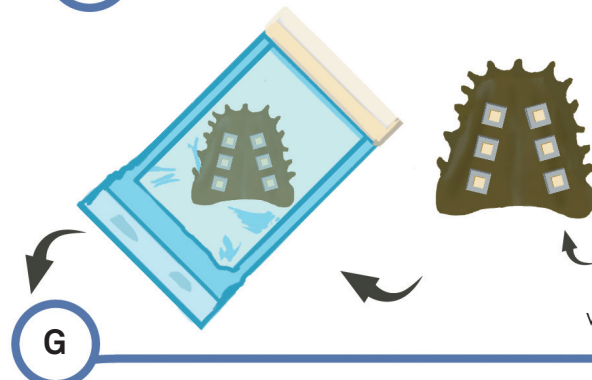

c
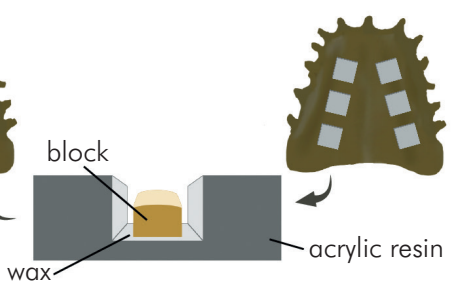

wax

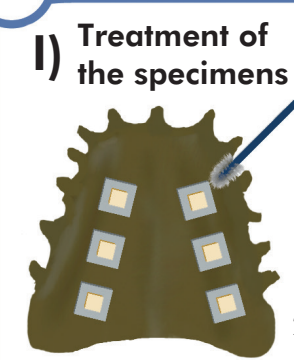

1) $\mathrm{TiF}_{4}$ varnish

2) $\mathrm{NaF}$ varnish

3) Placebo varnish

4) Negative control (withouth treatment)
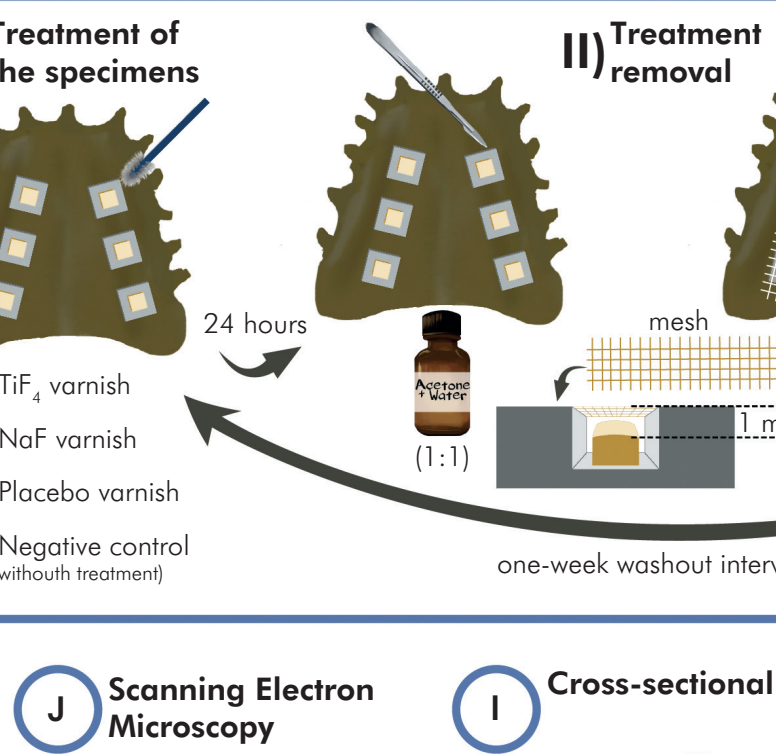

Cross-sectional Microhardness
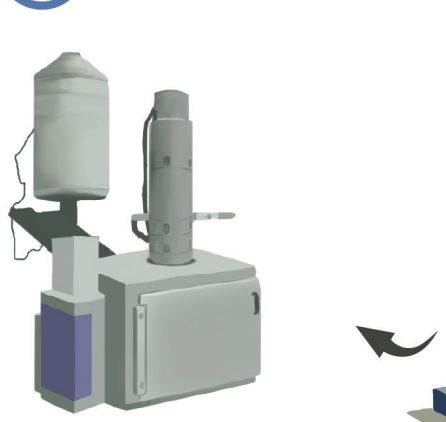

one-week washout interva

C Enamel Polishing
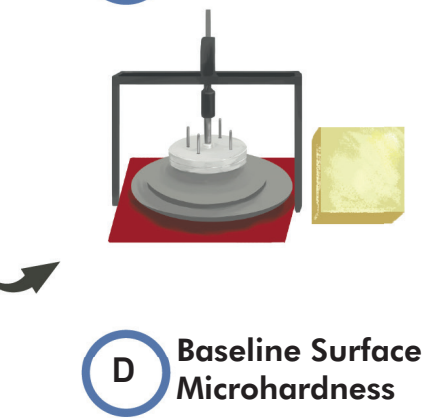

$100 \mu \mathrm{m}$

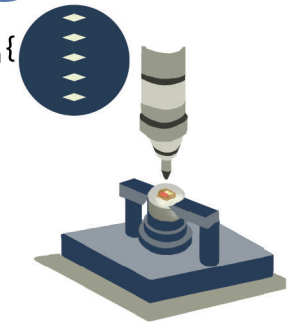

\section{III) Carbohydrate}

10 times a day for 14 days

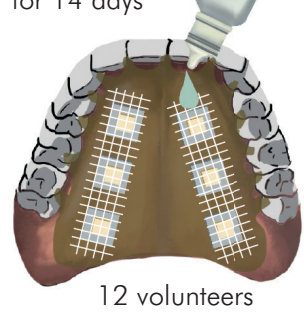

Final Surface Microhardness

Figure 1. Schematic diagram of process steps: A - Cutting Teeth; B - Dentin/Enamel Flattening; C - Enamel Polish; D - Baseline Surface Microhardness; E - Appliance Preparation; F - Ethylene Oxide Sterilization; G (I) - Treatment of the Specimens, (II) - Treatment Removal, (III) - Carbohydrate challenge; H - Final Surface Microhardness; I - Cross-sectional Microhardness; I -Scanning Electron Microscopy. 
The $4 \% \mathrm{TiF}_{4}$ varnish was formulated by dissolving $\mathrm{TiF}_{4}$ and resin products in ethanol 96\% (v/v, varnish vehicle) following a protocol from a previous study. ${ }^{15}$ The placebo varnish was produced in the same manner, but without $\mathrm{TiF}_{4}$. The NaF-Duraphat ${ }^{\circledR}$ varnish (Colgate-Palmolive Ind. e Com. Ltda., São Paulo, SP, Brazil) contained 5\% NaF, 33.1\% alcohol, natural resins (colophonium, mastix, shellac), wax, saccharin, and flavor. All varnishes were yellow and had a soft consistency.

\section{In situ protocol}

After treatment, volunteers wore the appliances for $24 \mathrm{~h}$. Next, the varnish was removed with a scalpel and a cotton swab was soaked in acetone diluted in water (1:1) ${ }^{16}$ Subsequently, a plastic mesh was used to cover the blocks in order to allow dental biofilm accumulation, and a $20 \%$ sucrose solution was applied to provide a carbohydrate challenge. Volunteers were instructed to remove the appliances from the oral cavity and to apply one drop of the sucrose solution on each enamel block 10 times/ day ${ }^{17}$ (Figure 1). The excess solution was removed using gauze, and the device was reinserted in the mouth 5 min later. Volunteers wore the appliances continuously, except during meals. The subjects received oral and written instructions on the schedule. They also received a diary for taking notes on the use of the device.

A one-week washout interval between the experimental stages was allowed to prevent any carryover effect. Throughout the experiment, including the washout periods, volunteers brushed their teeth and the appliance (except in the area of enamel slabs) with a fluoridated dentifrice (Colgate triple action; Colgate-Palmolive Ind. e Com. Ltda., São Paulo, $\mathrm{SP}$, Brazil) containing 1,100 $\mu \mathrm{g}$ of fluoride/g (NaF) and silica as abrasive agent. ${ }^{18}$ On the 14 th day of each stage, the blocks were removed for evaluation of enamel loss. The response variables were as follows: enamel surface microhardness loss (\%SML), enamel cross-sectional microhardness (CSMH), and energy dispersive X-ray spectrometry (EDS) analysis. The blocks were also analyzed qualitatively by scanning electron microscopy (SEM).

\section{Microhardness analysis}

After each stage, SMH of enamel blocks was measured again in all groups. A Knoop diamond indenter was used with a $50 \mathrm{~g}$ load for $5 \mathrm{~s}$, and five indentations were made at a distance of $100 \mu \mathrm{m}$ from the baseline indentations. The percentage of surface microhardness loss was calculated using the following equation: \%SML= (sound SMH - SMH after in situ treatment)/ sound $\mathrm{SMH}^{*} 100$.

\section{Cross-sectional microhardness analysis}

After the SMH test, the enamel blocks were tested for cross-sectional microhardness. All blocks were longitudinally sectioned in the middle of the fragment on a cutting machine (Buehler, Lake Bluff, IL, USA). One half was included in the resin stub and polished with silicon carbide discs (600- and 1,200-grit sandpapers, Buehler, Lake Bluff, IL, USA). The CSMH analyses were performed by a microhardness tester (HVS-1000, Time Group Inc., Beijing, China) using a Knoop diamond indenter and a static load of $25 \mathrm{~g}$ applied for $10 \mathrm{~s}$. Two sequences of 14 indentations were made $100 \mathrm{~mm}$ apart at depths of 10 to $60 \mathrm{~mm}$ at $10-\mathrm{mm}$ intervals, from 60 to $200 \mathrm{~mm}$ at 20 -mm intervals, and from 200 to $300 \mathrm{~mm}$, each at $100-\mathrm{mm}$ intervals from the outer enamel surface. $\Delta \mathrm{Z}(\mathrm{vol} \% \mathrm{x} \mu \mathrm{m})$ was used to calculate the mineral content. ${ }^{19}$

\section{Scanning electron microscopy and energy dispersive spectrometry}

After sectioning the blocks in the middle, the other half of the five enamel blocks from each group was randomly selected and prepared for EDS and SEM analysis (JEOL-JSM, 6460LV, Tokyo, Japan). ${ }^{16}$ The EDS analysis was performed with Kontron, a link and automatic image analyzer system, which provided the following double-way measurements: evaluation of the total area of the block and evaluation of three equidistant points (1-mm distance between points center, left, and right) on each selected block. The results were represented by the mean of the measured values.

After EDS analysis, the specimens were covered with a $30-\mu \mathrm{m}$ layer of gold in a vacuum apparatus. The specimens were examined (500x and 2,000x magnification) in low vacuum mode ( $45 \mathrm{~Pa})$, operating at $20 \mathrm{kV}$, with analysis of backscattered electrons. 


\section{Statistical analysis}

The normal distribution of data was checked for all the tested variables using the Shapiro-Wilk test. One-way ANOVA was used to compare the SMH values for all blocks before the experiment. Student's paired t-test was used to compare SMH before and after the experiment. Differences in \%SML and $\mathrm{CSMH}(\Delta \mathrm{Z})$ among treatments were tested using the repeated-measures ANOVA. The SPSS software (version 20.0) was used for the statistical analysis and the significance level was set at $5 \%$.

\section{Results}

\section{Microhardness loss}

When comparing the $\mathrm{SMH}$ values for all enamel blocks before the experiment, no statistically significant difference was observed among groups, thus demonstrating data homogeneity $(p=0.164$; one-way ANOVA).

When SMH values before and after 14 days of the experiment were compared for each treatment (Table 1), a statistically significant decrease for all treatment groups was observed ( $p=0.000$; Student's paired t-test). SMH results after the experiment showed differences between the treatments; and although all groups had a decrease in hardness, this outcome did not occur equally. The group treated with the $\mathrm{TiF}_{4}$ varnish presented lower \%SML (30.52 \pm 10.03$)$ than the negative control $(62.58 \pm 21.18)$ and the placebo $(52.08 \pm 23.35)$ treatments. Both differences were statistically significant according to the repeated-measures ANOVA, with p-values of 0.003 and 0.044 , respectively. There was no statistical difference between $\mathrm{NaF}$ varnish and placebo or negative control groups $(\mathrm{p}>0.05$; repeated-measures ANOVA). In addition, no statistically differences were observed between $\mathrm{TiF}_{4}$ and $\mathrm{NaF}$ varnishes $(\mathrm{p}=0.085$; repeated-measures ANOVA).

When CSMH $(\Delta \mathrm{Z})$ was analyzed after 14 days, there were statistically significant differences between the $\mathrm{TiF}_{4}$ varnish and control groups $(\mathrm{p}=0.0001$; repeated-measures $\mathrm{ANOVA}$ ) or between the $\mathrm{TiF}_{4}$ varnish and placebo groups $(p=0.003$; repeated-measures ANOVA). The NaF varnish group also differed from the control and placebo groups $(p=0.0001$ and $p=0.001$, respectively; repeated-measures ANOVA). No statistically significant difference was found between the placebo and negative control groups ( $p>0.05$; repeated-measures ANOVA).

Only $\mathrm{TiF}_{4}$ varnish was able to inhibit surface demineralization $(\mathrm{p}<0.05)$ (Table 1). However, $\mathrm{TiF}_{4}$ varnish had similar results to those of $\mathrm{NaF}$ varnish regarding the decrease in subsurface demineralization ( $p$ > 0.05; repeated-measures ANOVA) (Table 1).

\section{SEM/EDS analysis}

The enamel specimens from all groups were analyzed descriptively based on SEM findings, which allowed observing the characteristics of the surface enamel.

The images of the negative control and placebo groups (Figures 2A and 2B) showed more porous enamel surfaces characterized by surface mineral loss, differing from the images obtained for the $\mathrm{NaF}$ and $\mathrm{TiF}_{4}$ groups (Figures $2 \mathrm{C}$ and 2D). However, the images obtained for the control group showed more mineral loss than in the placebo group (Figure 2A).

Only in the specimens treated with the $\mathrm{TiF}_{4}$ varnish, there was a titanium dioxide film on most of the

Table 1. Surface microhardness analysis before and after the experiments, percentage of enamel surface microhardness loss and cross-sectional microhardness analysis according to the treatments - 14 days after the treatments (means \pm standard deviation)

\begin{tabular}{lcccc}
\hline \multirow{2}{*}{ Treatments } & \multicolumn{3}{c}{ SMH analysis } & \multicolumn{2}{c}{ CSMH analysis } \\
\cline { 2 - 5 } & \multicolumn{1}{c}{ SMH Before } & SMH After & $\%$ SML & $\Delta Z$ \\
\hline NaF varnish & $345.63 \pm 17.87^{\mathrm{A}, \mathrm{a}}$ & $180.95 \pm 67.93^{\mathrm{B}, \mathrm{a}}$ & $47.13 \pm 20.73^{\mathrm{a}, \mathrm{b}}$ & $720.34 \pm 635.40^{\mathrm{a}}$ \\
$\mathrm{TiF}_{4}$ varnish & $336.14 \pm 15.99^{\mathrm{A}, \mathrm{a}}$ & $233.44 \pm 35.85^{\mathrm{B}, \mathrm{b}}$ & $30.52 \pm 9.93^{\mathrm{b}}$ & $519.73 \pm 478.00^{\mathrm{a}}$ \\
Placebo varnish & $334.31 \pm 13.83^{\mathrm{A}, \mathrm{a}}$ & $124.82 \pm 68.37^{\mathrm{B}, \mathrm{a}, \mathrm{c}}$ & $52.08 \pm 21.10^{\mathrm{a}}$ & $1,603.00 \pm 1225.40^{\mathrm{b}}$ \\
Negative control & $344.72 \pm 11.74^{\mathrm{A}, \mathrm{a}}$ & $165.24 \pm 82.28^{\mathrm{B}, \mathrm{c}}$ & $62.58 \pm 23.27^{\mathrm{a}}$ & $1,638.39 \pm 748.33^{\mathrm{b}}$ \\
\hline
\end{tabular}

Means followed by different letters are statistically different $(p<0.05)$. Uppercase letters show differences before and after the experiment in each group, and lowercase letters in the same column show differences between the treatments. 

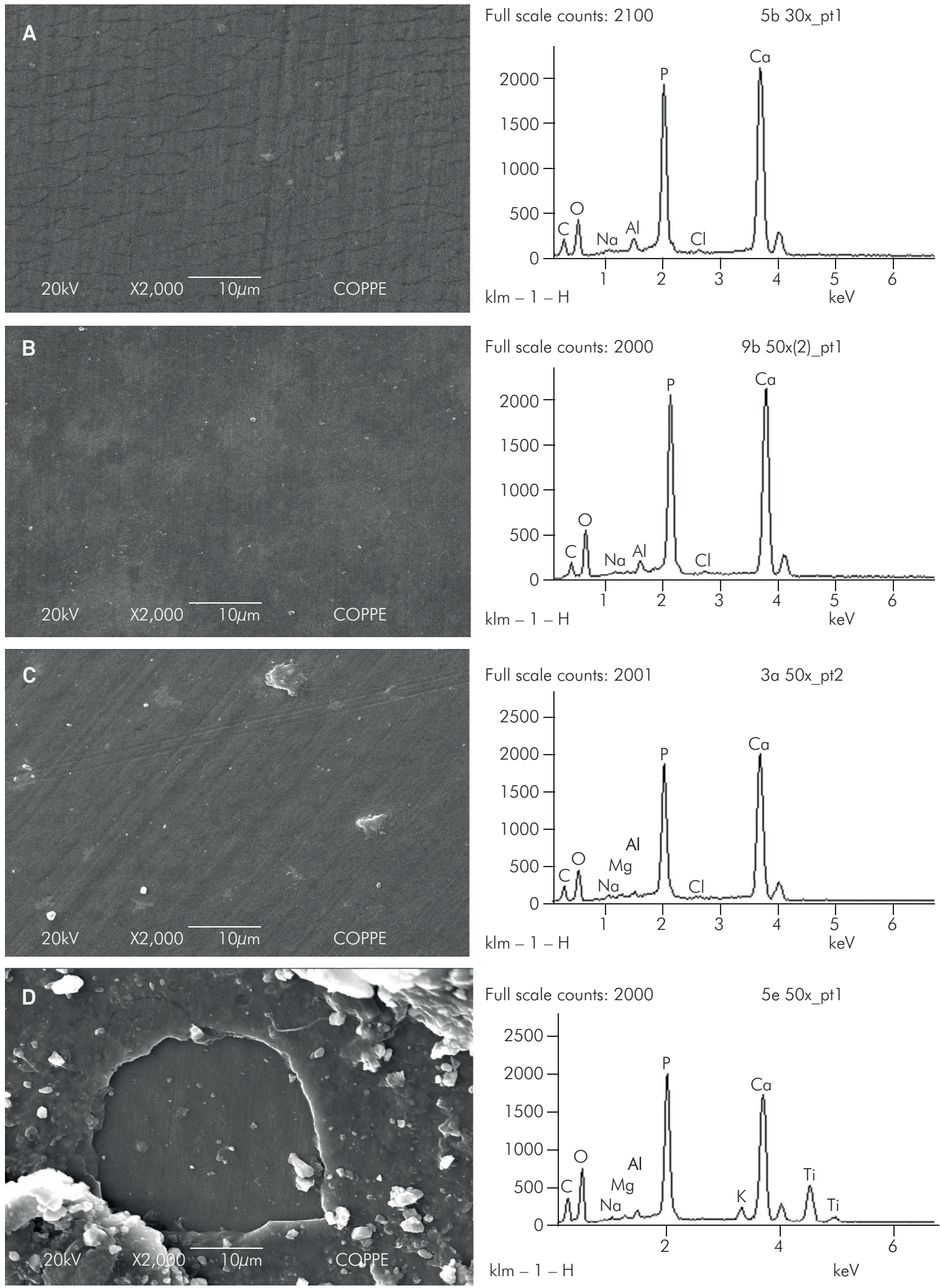

Figure 2. Surface SEM images of enamel samples after 14 days of treatment at 2000x (left) and EDS analysis (right). (a) Negative control, (b) Placebo varnish, (c) NaF varnish and (d) $\mathrm{TiF}_{4}$ varnish. 
surface (Figure 2D). When comparing the images of the specimens treated with $\mathrm{NaF}$ and $\mathrm{TiF}_{4}$ (Figures 2C and 2D), enamel specimens treated with $\mathrm{TiF}_{4}$ had less damage on their surfaces than those treated with $\mathrm{NaF}$.

The chemical analysis (EDS) revealed the presence of titanium (Ti) in all samples after $\mathrm{TiF}_{4}$ treatment (Figure 2D). Fluoride was not found after the experiment in samples treated with $\mathrm{TiF}_{4}$ and $\mathrm{NaF}$ varnishes. Carbon, oxygen, sodium, phosphorus, and calcium basically kept the same percentages (Table 2).

\section{Discussion}

In cases of high caries risk, professional topical fluoride application has been an excellent alternative because of its high fluoride ion concentration. ${ }^{20,21}$ Fluoride varnishes are considered to be an efficient delivery system, used in clinical dentistry to minimize the risks of fluoride toxicity. An advantage of varnishes is their ability to keep the active compound in contact with tooth enamel while allowing for safe use of high fluoride concentrations. ${ }^{20}$ Clinical studies with fluoride varnishes have demonstrated a reduction in the incidence of dental caries. ${ }^{20}$ In the present study, a severe cariogenic challenge was performed in order to promote fast enamel demineralization and simulate high caries risk.

Two different fluoride varnishes were used: one with sodium fluoride (a commercial $\mathrm{NaF}$ varnish Duraphat ${ }^{\circledR}, 2.26 \% \mathrm{~F}$ ) and another one with titanium tetrafluoride $\left(\mathrm{TiF}_{4}\right.$ varnish, $\left.2.45 \% \mathrm{~F}\right)$. Furthermore, a placebo varnish with the same composition as the $\mathrm{TiF}_{4}$ varnish but without fluoride was also used. Nobrega et al. ${ }^{15}$ observed this $\mathrm{TiF}_{4}$ varnish maintained fluorapatite (FA) and $\mathrm{CaF}_{2}$ levels after one year of storage; however, there was an initial decrease in $\mathrm{CaF}_{2}$ formation.
The varnishes were applied only once and were removed after $24 \mathrm{~h}$ to simulate the clinical situation in which a single professional application had been applied and the material had been removed during toothbrushing or mastication approximately $24 \mathrm{~h}$ thereafter. Nevertheless, in all varnish-treated groups, there were traces of varnish, even in the placebo group. This outcome is consistent with previous studies that found varnish remnants even within several days after the end of the experiment. ${ }^{21}$

In the literature, some studies showed $\mathrm{TiF}_{4}{ }^{7,8,10}$ was efficient against dental caries. The present in situ study demonstrated the $\mathrm{TiF}_{4}$ varnish could inhibit enamel surface and subsurface demineralization under severe cariogenic challenge.

The $\mathrm{TiF}_{4}$ varnish was effective in protecting the enamel from acid dissolution after 14 days, as it had a lower \%SML after high cariogenic challenge. Notwithstanding, the results demonstrated the $\mathrm{NaF}$ varnish was unable to protect the dental enamel from surface mineral loss. Conversely, Magalhaes et al. ${ }^{6}$ showed $4 \% \mathrm{TiF}_{4}$ varnish was less effective than $\mathrm{NaF}$ varnish in preventing surface demineralization.

However, our results confirmed that $\mathrm{NaF}$ varnish was able to decrease subsurface enamel demineralization to a similar degree as that of the $\mathrm{TiF}_{4}$ varnish, in agreement with Magalhaes et al. ${ }^{6}$ and Comar et al. ${ }^{5}$

It has been speculated that titanium ions might substitute calcium in the apatite lattice and form a titanium phosphate compound, leading to higher acid resistance of dental hard tissues. ${ }^{22}$ In addition, $\mathrm{TiF}_{4}$ has the ability to form an acid-resistant titanium dioxide surface film when in contact with the dental enamel surface. . $9,10,11^{2}$

The protective effect of the amorphous acid-resistant film might be mainly related to its ability to act as

Table 2. EDS analysis of the surface of enamel blocks; chemical elements are shown according to the treatments (means \pm standard deviation).

\begin{tabular}{lccccccc}
\hline Treatments & $\mathrm{C}$ & $\mathrm{O}$ & $\mathrm{F}$ & $\mathrm{Na}$ & $\mathrm{P}$ & $\mathrm{Ca}$ & $\mathrm{Ti}$ \\
\hline NaF varnish & $30.5 \pm 6.9$ & $29.7 \pm 2.6$ & 0.0 & $0.5 \pm 0.1$ & $13.1 \pm 1.6$ & $25.5 \pm 3.0$ & 0.0 \\
$\mathrm{TiF}_{4}$ varnish & $36.5 \pm 9.6$ & $29.1 \pm 5.0$ & 0.0 & $0.4 \pm 0.1$ & $10.7 \pm 1.4$ & $19.0 \pm 3.5$ & $4.8 \pm 2.0$ \\
Placebo varnish & $24.2 \pm 4.3$ & $35.5 \pm 2.9$ & 0.0 & $0.4 \pm 0.1$ & $13.6 \pm 0.8$ & $25.5 \pm 0.9$ & 0.0 \\
Negative control & $21.3 \pm 3.0$ & $36.7 \pm 3.2$ & 0.0 & $0.4 \pm 0.1$ & $14.1 \pm 0.4$ & $26.3 \pm 1.1$ & 0.0 \\
\hline
\end{tabular}


a physical diffusion barrier. Moreover, the layer is rich in titanium and fluoride, and it might also act as a reservoir for fluoride ions.,10,11 SEM images and EDS analysis showed all samples treated with $\mathrm{TiF}_{4}$ varnish were able to increase titanium concentration on the enamel surface. Although the incorporated titanium had been lost during the experimental period, Tveit et al. ${ }^{11}$ suggest the $\mathrm{TiO}_{2}$ layer slowed down and hindered demineralization, possibly increasing resistance of tooth enamel against acid challenges.

The formation of $\mathrm{TiO}_{2}$ combines with the presence of $\mathrm{CaF}_{2}$, likely reducing demineralization. Topical fluorides can react with enamel to form reaction products, which can be loosely $\left(\mathrm{CaF}_{2}\right)$ or firmly (fluorapatite) bound to enamel and could interfere with the demineralization and remineralization during the carious process. ${ }^{3,11}$ Though fluoride was not found in the EDS analysis, $\mathrm{TiF}_{4}$ hydrolysis can result in the formation of many fluoride complexes. ${ }^{23}$ Nóbrega et al. ${ }^{15}$ show the capacity of this $\mathrm{TiF}_{4}$ varnish to form reaction products such as $\mathrm{FA}$ and $\mathrm{CaF}_{2}$. Probably due to the mineral exchange process that occurs between the tooth and the biofilm, ${ }^{18}$ loss of fluoride may have occurred on the biofilm, not allowing its measurement on the surface of the dental element after 14 days.

The low $\mathrm{pH}$ of the $\mathrm{TiF}_{4}$ products could be a hindrance and their use by patients should be

\section{References}

1. Scheifele E, Studen-Pavlovich D, Markovic N. Practitioner's guide to fluoride. Dent Clin North Am. 2002;46(4):831-46. https://doi.org/10.1016/S0011-8532(02)00019-8

2. Iheozor-Ejiofor Z, Worthington HV, Walsh T, O'Malley L, Clarkson JE, Macey R et al. Water fluoridation for the prevention of dental caries. Cochrane Database Syst Rev. 2015;6(6):CD010856. https://doi.org/10.1002/14651858.CD010856.pub2

3. Øgaard B. CaF(2) formation: cariostatic properties and factors of enhancing the effect. Caries Res. 2001;35 Suppl 1:40-4. https://doi.org/10.1159/000049109

4. Alcântara PC, Alexandria AK, Souza IP, Maia LC. Energy dispersive $\mathrm{x}$-ray spectroscopy evaluation of demineralized human enamel after titanium tetrafluoride application. J Clin Pediatr Dent. 2015;39(2):124-7. https://doi.org/10.17796/icpd.39.2.778531q560886x5r discouraged, owing to their side effects on soft tissues. Even though the $\mathrm{TiF}_{4}$ varnish remains on the enamel surface for $24 \mathrm{~h}$, longer application time of varnish products compared with $\mathrm{TiF}_{4}$ solution could have offered possible differences in fluoride precipitation, ${ }^{5}$ since a short application time might limit $\mathrm{CaF}_{2}$ and $\mathrm{TiO}_{2}$ formation. In addition, varnish products have a smaller contact with adjacent tissues due to their adhesion to the dental surface. However, caution should be taken when drawing conclusions from in vivo studies; more investigations are needed to ratify these findings.

Based on the results of this study, the null hypothesis was rejected, since the $4 \% \mathrm{TiF}_{4}$ varnish was able to reduce surface and subsurface enamel demineralization under cariogenic challenge.

\section{Acknowledgments}

The authors acknowledge the financial support from CAPES, FAPERJ (E-26/201.316/2014), and CNPQ (302800/2012-3, 152231/2016-1 and 303535/2016-4). The authors gratefully thank all the volunteers who participated in this study. Furthermore, special thanks should be given to Viviane Santos da Silva Pierro and Tiago Cruz de França for their support throughout the experiment and to Irlan de Almeida Freires for suggesting improvements in the English language.

5. Comar LP, Wiegand A, Moron BM, Rios D, Buzalaf MA, Buchalla $W$ et al. In situ effect of sodium fluoride or titanium tetrafluoride varnish and solution on carious demineralization of enamel. Eur J Oral Sci. 2012;120(4):342-8. https://doi.org/10.1111/j.1600-0722.2012.00968.x

6. Magalhães AC, Comar LP, Rios D, Delbem AC, Buzalaf MA. Effect of a $4 \%$ titanium tetrafluoride (TiF4) varnish on demineralisation and remineralisation of bovine enamel in vitro. J Dent. 2008;36(2):158-62. https://doi.org/10.1016/i.jdent.2007.12.001

7. Nassur C, Alexandria AK, Pomarico L, de Sousa VP, Cabral LM, Maia LC. Characterization of a new TiF(4) and $\beta$-cyclodextrin inclusion complex and its in vitro evaluation on inhibiting enamel demineralization. Arch Oral Biol. 2013;58(3):239-47. https://doi.org/10.1016/j.archoralbio.2012.11.001 
8. Alcântara PC, Alexandria AK, Souza IP, Maia LC. In situ effect of titanium tetrafluoride and sodium fluoride on artificially decayed human enamel. Braz Dent J. 2014;25(1):28-32. https://doi.org/10.1590/0103-6440201302329

9. Gu Z, Li J, Söremark R. Influence of tooth surface conditions on enamel fluoride uptake after topical application of TiF4 in vitro. Acta Odontol Scand. 1996;54(5):279-81. https://doi.org/10.3109/00016359609003538

10. Büyükyilmaz T, Ogaard B, Rølla G. The resistance of titanium tetrafluoride-treated human enamel to strong hydrochloric acid. Eur J Oral Sci. 1997 Oct;105(5 Pt 2):473-7. https://doi.org/10.1111/j.1600-0722.1997.tb00233.x

11. Tveit $A B$, Tötdal $B$, Klinge $B$, Nilvéus R, Selvig KA. Fluoride uptake by dentin surfaces following topical application of TiF4, NaF and fluoride varnishes in vivo. Caries Res. 1985;19(3):240-7. https://doi.org/10.1159/000260850

12. Medeiros MI, Carlo HL, Lacerda-Santos R, Lima BA, Souza FB, Rodrigues JA et al. Thickness and nanomechanical properties of protective layer formed by TiF4 varnish on enamel after erosion. Braz Oral Res. 2016;30(1):S1806-83242016000100264. https://doi.org/10.1590/1807-3107BOR-2016.vol30.0075

13. Zero DT. In situ caries models. Adv Dent Res. 1995;9(3):214-30. https://doi.org/10.1177/08959374950090030501

14. Alexandria AK, Meckelburg NA, Puetter UT, Salles JT, Souza IP, Maia LC. Do pediatric medicines induce topographic changes in dental enamel? Braz Oral Res. 2016;30(1):30. https://doi.org/10.1590/1807-3107BOR-2016.vol30.0011

15. Nóbrega CB, Fujiwara FY, Cury JA, Rosalen PL. TiF(4) varnish-A (19)F-NMR stability study and enamel reactivity evaluation. Chem Pharm Bull (Tokyo). 2008;56(1):139-41. https://doi.org/10.1248/cpb.56.139
16. Alexandria AK, Vieira TI, Pithon MM, da Silva Fidalgo TK, Fonseca-Gonçalves A, Valença AM et al. In vitro enamel erosion and abrasion-inhibiting effect of different fluoride varnishes. Arch Oral Biol. 2017;77:39-43. https://doi.org/10.1016/j.archoralbio.2017.01.010

17. Cenci MS, Tenuta LM, Pereira-Cenci T, Del Bel Cury AA, ten Cate JM, Cury JA. Effect of microleakage and fluoride on enamel-dentine demineralization around restorations. Caries Res. 2008;42(5):369-79. https://doi.org/10.1159/000151663

18. Cury JA, Rebelo MA, Del Bel Cury AA, Derbyshire MT, Tabchoury CP. Biochemical composition and cariogenicity of dental plaque formed in the presence of sucrose or glucose and fructose. Caries Res. 2000;34(6):491-7. https://doi.org/10.1159/000016629

19. Kielbassa AM, Müller U, García-Godoy F. In situ study on the caries-preventive effects of fluoride-releasing materials. Am J Dent. 1999;12(Spec No):S13-4.

20. Marinho VC, Worthington HV, Walsh T,

Clarkson JE. Fluoride varnishes for preventing dental caries in children and adolescents. Cochrane Database Syst Rev. 2013;7(7):CD002279. https://doi.org/10.1002/14651858.CD002279.pub2

21. Maia LC, de Souza IP, Cury JA. Effect of a combination of fluoride dentifrice and varnish on enamel surface rehardening and fluoride uptake in vitro. Eur J Oral Sci. 2003;111(1):68-72. https://doi.org/10.1034/j.1600-0722.2003.00007.x

22. Ribeiro CC, Gibson I, Barbosa MA. The uptake of titanium ions by hydroxyapatite particles-structural changes and possible mechanisms. Biomaterials. 2006;27(9):1749-61. https://doi.org/10.1016/j.biomaterials.2005.09.043

23. Buslaev YA. D. D. S., Ragsdale R. O. Hydrolysis of titanium tetrafluoride. Inorganic. Chemistry. 1967;6(12):2208-12. 